American Journal of Infectious Diseases 5 (4): 320-323, 2009

ISSN 1553-6203

(C) 2009 Science Publications

\title{
Screening of Breast Mass in Iraqi Females: Al-Kindy Hospital Breast Clinic
}

\author{
Wijdan Akram \\ Al-Kindy College of Medicine, University of Baghdad, Baghdad, Iraq
}

\begin{abstract}
Problem statement: The aim of this study is to present the findings of a retrospective analysis in females with breast mass, the character of the women and the risk factors of breast cancer at Al-Kindy Breast Clinic Center. Approach: Data were collected during 2 months period using special form of questioner. The total number of studied sample was 60, which includes female patients living in Baghdad. Results: The highest prevalence of developing breast mass at age group 36-45 years, the majority of these women are housewives $(81.7 \%)$, about $(31.7 \%)$ of the included sample were illiterate and only $10 \%$ graduated from college. $(58.3 \%)$ of the studied sample did not use contraception, while $(30 \%)$ of patients with breast mass had breast feeding on the other hand $(70 \%)$ did not had breast feeding, by self examination, $(11.7 \%)$ could not found the mass by themselves, $(28.3 \%)$ had a mass in the right breast, $(50 \%)$ had a mass in the left breast while $(10 \%)$ had the mass in both breasts. Conclusion: The study showed a high level of practice of breast-self examination among women in the sample under consideration, breast masses were more occurring at the third and fourth decades of life, the number of children may affect the development of breast mass and combined oral contraceptive has small increased risk of breast mass.
\end{abstract}

Key words: Breast mass, sensitivity, specificity

\section{INTRODUCTION}

Cancer of the breast represents $10 \%$ of all cancers diagnosed worldwide annually and constituted $22 \%$ of all new cancers in women. The burden of breast cancer has increased steadily, almost doubling, in terms of estimated new cases annually over a 20 year span. Breast cancer was third in frequency in men and women taken as a group and by far it is the most prevalent cancer in women with more than one million cases and nearly 600,000 deaths occurring worldwide annually ${ }^{[1]}$. The incidence rates are increasing in all countries with available statistics and since women are at risk from the ages of late 30's, the impact of the disease is magnified ${ }^{[2]}$. According to the Regional Office database and data from many countries of the region $^{[1,3,4]}$ the breast cancer is the most common malignancy in the region comprising $12-30 \%$ of all cases Retrospective demographic regional studies ${ }^{[4,5]}$ have shown that most patients with breast cancer present for the first time at stages two to three Studies of the etiology of breast cancer have failed to identify feasible primary prevention strategies suitable for use in the general population, so, reducing mortality from breast cancer through early detection has become a high priority $^{[2]}$. In a retrospective study to determine the incidence of breast cancer varies greatly around the world, being lower in less-developed countries and greatest in the more-developed countries. the epidemiology of breast carcinoma in various countries or ethnic groups ${ }^{[9]}$.

\section{MATERIALS AND METHODS}

\section{Design: Retrospective cohort study: Place: Al-Kindy Breast Clinic Center, Baghdad, Iraq.}

Time of study: January-end of February 2009 have previous screening mammography, $65.7 \%$ were diagnosed with "advanced" breast cancer (stages II-IV), while only $39.9 \%$ who had previous screening mammography were diagnosed with advanced breast cancer $(\mathrm{p}<0.001)^{[5]}$.

Breast diseases are showing a rising trend worldwide. A number of studies have been done in order to know the magnitude of the problem ${ }^{[6,7]}$. Breast carcinoma ranks first among the malignant tumors affecting females in many parts of the world ${ }^{[8]}$. There is a wide variation in the spectrum of breast diseases and a retrospective study was conducted on 60 female patients living in Baghdad, Iraq who presented to AlKindy Breast Clinic Center. In this study the records of all female with breast mass were analyzed over a period of two months and data were abstracted from the charts of these patients. 
A 3-parts structured questionnaire (demographic data, general knowledge and early detection) based on fundamental knowledge of breast cancer and early detection was used as pre-post test instrument. Statistical analysis: The data were entered and analyzed using SPSS 11.0.0 statistical software after checking the data for missing values descriptive statistics were generated for all variables.

\section{RESULTS}

The data covered the two months interval, 60 female patients were presented to Al-Kindy Breast Clinic Center with breast mass, sample group of the study were analyzed according to age group as shown in Fig. 1. The findings, that the highest prevalence of developing breast mass at age group 36-45 years, the majority of these women are housewives about $(81.7 \%)$.

Regarding education (31.7\%) are illiterate and only $10 \%$ graduated from college so, it is lowest among college learning women but this may be due to the fact that only 6 women included in the study graduated. As shown in Table 1.

According to marital status, the highest percentage $(80 \%)$ was married. Of which $50 \%$ of these married women have 5 or less than 5 children as shown in Table 2.

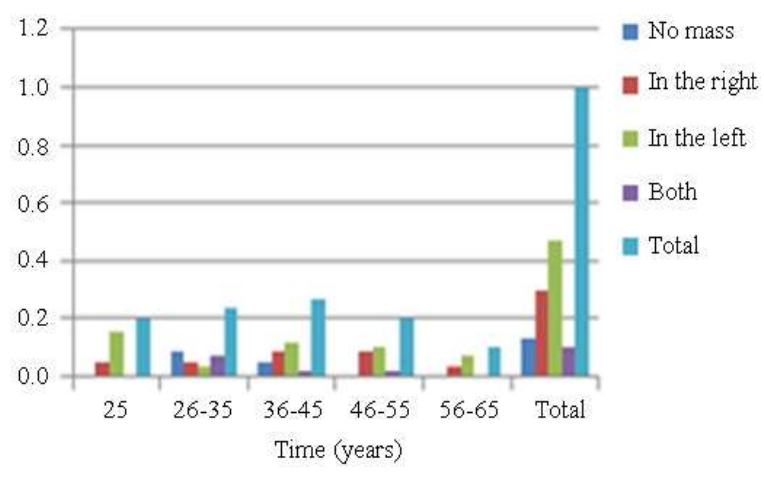

Fig. 1: Association between breast mass and age group

Table 1: Association between breast mass and level of education

\begin{tabular}{lccccc}
\hline $\begin{array}{l}\text { BM and } \\
\text { level of } \\
\text { education }\end{array}$ & $\begin{array}{c}\text { Illiterate } \\
(\%)\end{array}$ & $\begin{array}{l}\text { Primary } \\
(\%)\end{array}$ & $\begin{array}{l}\text { Secondary } \\
(\%)\end{array}$ & $\begin{array}{l}\text { College } \\
(\%)\end{array}$ & $\begin{array}{l}\text { Total } \\
(\%)\end{array}$ \\
\hline No mass & 5.0 & 3.3 & 3.3 & & 11.6 \\
In the right & 5.0 & 10.0 & 10.0 & 3.3 & 28.3 \\
In the left & 20.0 & 13.3 & 10.0 & 6.7 & 50.0 \\
Both & 1.7 & 1.7 & 6.7 & & 10.1 \\
Total & 31.7 & 28.3 & 30.0 & 10.0 & 100.0 \\
\hline
\end{tabular}

Concerning the contraception use $58.3 \%$ did not use contraception, $28.3 \%$ use pills, 8.3 use injections, $5 \%$ use both ( pill and injection).

Concerning menarche, $95 \%$ had menarche at age less than 15 while $5 \%$ had it at age 15 or more than 15 and according to regularity of menstrual cycle, $31.7 \%$ had irregular menstrual cycle while $68.3 \%$ had a regular cycle.

About $30 \%$ of patient with breast mass had breast feeding while $70 \%$ did not had breast feeding. $48.3 \%$ of these patients with breast feeding had a period of lactation about one year, $18.3 \%$ had a period of two years and 3.3\% had a period of more than two years.

Most of women having a mass having breast feeding of not less than one year Most of patients presented with breast mass have no family history $(81.7 \%)$, while $18.3 \%$ with positive family history. According to the discharge from the nipple $86.7 \%$ had no discharge, $11.7 \%$ had non bloody discharge and $1.6 \%$ had a bloody discharge Fig. 2.

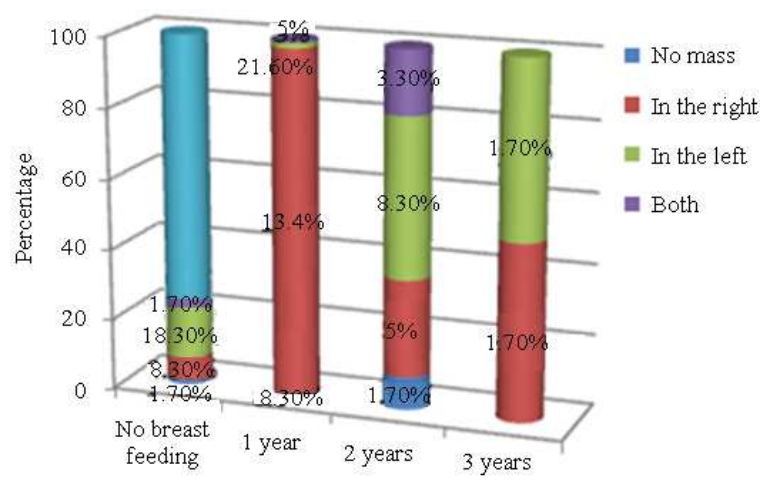

Fig. 2: Association between breast mass and period of breast feeding

Table 2: Association between breast mass and the number of children

\begin{tabular}{lcccc}
\hline $\begin{array}{l}\text { Breast mass and } \\
\text { no of children }\end{array}$ & $\begin{array}{l}\text { No } \\
\text { children }(\%)\end{array}$ & $\begin{array}{l}<5 \\
(\%)\end{array}$ & $\begin{array}{l}\geq 5 \\
(\%)\end{array}$ & Total \\
\hline No mass & 1.7 & 8.3 & 1.7 & 11.7 \\
In the right & 6.7 & 15.0 & 6.7 & 28.4 \\
In the left & 13.3 & 20.0 & 16.6 & 49.9 \\
Both & 1.7 & 6.6 & 1.7 & 10.0 \\
Total & 34.8 & 49.9 & 11.7 & 96.4 \\
\hline
\end{tabular}

Table 3: Sensitivity and specificity of diagnosing a breast mass with breast self examination

\begin{tabular}{llll}
\hline $\begin{array}{l}\text { Test } \\
\text { result }\end{array}$ & $\begin{array}{l}\text { Diseased } \\
\text { (breast mass) }\end{array}$ & $\begin{array}{l}\text { No } \\
\text { disease }\end{array}$ & Total \\
\hline Positive & 18 & 0 & 18 \\
Negative & 35 & 7 & 42 \\
Total & 53 & 7 & 60 \\
\hline Sensitivity; $18 / 53=33 \% ;$ Specificity; $7 / 7=100 \%$ &
\end{tabular}


Am. J. Infect. Dis., 5 (4): 320-323, 2009

Table 4: Sensitivity and specificity of $\mu \sec ^{-1}$ screening test to breast

\begin{tabular}{|c|c|c|c|}
\hline $\begin{array}{l}\text { Screening } \\
\text { test }\end{array}$ & $\begin{array}{l}\text { Disease } \\
\text { (breast mass) }\end{array}$ & $\begin{array}{l}\text { No disease } \\
\text { (no breast mass) }\end{array}$ & Total \\
\hline Positive & 43 & 3 & 46 \\
\hline Negative & 10 & 4 & 14 \\
\hline Total & 53 & 7 & 60 \\
\hline
\end{tabular}

Sensitivity: 43/53 = 0.811; Specificity: 4/7 $=0.57$

Mass results: About $70 \%$ had no mass while the remaining $30 \%$ had a mass, by self examination, $11.7 \%$ could not found the mass by themselves, $28.3 \%$ had a mass in the right breast, $50 \%$ had a mass in the left breast while 10\% had the mass in both breasts (Table 3 and 4).

\section{DISCUSSION}

The etiology of breast cancer is uncertain and adequate primary prevention is not possible. Thus early detection measures remain the first priority. More than $50 \%$ of total breast cancer diagnosed annually is found in premenopausal women, creating the need to initiate breast cancer screening programs in this population and one of these measures include breast self examination ${ }^{[10]}$, there has been much debate recently about the role of breast self examination as an effective screening practice to reduce the risk of death from breast cancer ${ }^{[11]}$, in our study among the total sample, approximately $11.7 \%$ never performed breast self examination while $88.3 \%$ found a mass by self examination, the peak age group of developing mass is 36-45 years, this result going with Malaysian research at 2006, the age group most commonly affected were those between $40-49$ years about $81.4 \%$ patients presented with mass in breast and the mass was mainly self detected $97.3 \%$.

Women between the ages of 40 and 69 have a 30\% chance of a false-positive screening mammogram or breast examination over a 10 year period. 14 Falsepositive results lead to additional testing, increased cost and unnecessary anxiety. The rates of false-positive screening tests are higher for younger women because fewer of their breast masses are malignant. Women need to understand the possibility of obtaining false-positive results when they have screening ${ }^{[12]}$.

Ultrasonographic screening is useful to differentiate between solid and cystic breast masses when a palpable mass is not well seen on a mammogram. Ultrasonography is especially helpful in young women with dense breast tissue when a palpable mass is not visualized on a mammogram. Ultrasonography is not to be used for routine screening, primarily because micro calcifications are not visualized and the yield of carcinomas is negligible $^{[13]}$.
Data suggests that breast cancer in Saudi Arabia occurs in a relatively younger age group compared with industrialized countries. The mean age of Saudi women with breast cancer is 47 years as compared with 54 years in Western Europe and America ${ }^{[7]}$ and this goes with our study.

Fifty percent of women presented with mass have less than 5 children while $26 \%$ have more than 5 children. Women taking oral contraceptive have small increased risk of breast mass about $26 \%$, the regularity of menstrual cycle among patients is $68 \%$, patients with breast feeding $70 \%$ and those with family history about $18 \%$, in contrast to study done in Jordan at 2007 , the effect of oral contraception is $4 \%$, the regularity of menstrual cycle about $85 \%$, breast feeding patients about $1.25 \%$ and lastly those who had have family history of breast cancer about $5 \%{ }^{[14]}$. Findings of our study and from other studies in Pakistan 15-18 related to breast cancer are comparable to those available in other Middle Eastern countries such as Saudi Arabia 19 and Jordan.22 the similarities shared in these studies with breast cancer include younger age as compared to the western literature 3, 4. However, lack of awareness regarding breast cancer and delay in seeking medical advice may be additional factors contributing to this late presentation ${ }^{[15]}$.

The descriptive epidemiology of breast cancer has demonstrated a rapid increase in the incidence rates in developing countries. Identification of the contributing factors for the increasing rate would contribute substantially to our understanding of the epidemiology of breast cancer ${ }^{[16]}$. Environmental factors rather than genetic factors have been considered as the reason for variation in breast cancer rates among countries ${ }^{[16]}$.

Socioeconomic development is normally associated with changing lifestyle, disease pattern and increasing life expectancy. These problems can be tackled by the implementation of breast cancer screening program in our country which is required for early detection of this tumor at a stage when it is treatable. Further work is needed to put more light on the natural history of breast carcinoma in Iraqi females, which can be fulfilled by multicenter-based studies and a national tumor registry system ${ }^{[17]}$.

\section{CONCLUSION}

This study highlights some of the unique epidemiological features of breast cancer seen in this region; younger age, large tumor size and advanced stage at presentation. In contrast to data from the West, where more than half of breast cancer patients are above 50 years of age. A younger age at presentation 
may be one of the reasons for the advanced stage of disease seen in our patients.

\section{Recommendations:}

- Educational program conducted to all women would be an interesting thing to increase the awareness about breast cancer

- Screening method for women of any age

- Surveillance program be developed in consultation with women's general practitioner and or specialist this might include regular clinical breast imaging with mammography and/or ultrasound

- Increase the physician's knowledge about breast cancer and early detection by educational program

- Annual mammograms and clinical breast examinations are recommended for women older than 40 years. Women older than 20 years should be encouraged to do monthly breast selfexaminations and women between 20 and 39 years of age should have a clinical breast examination every three years. These guidelines are modified for women with risk factors, particularly those with a strong family history of breast cancer

\section{REFERENCES}

1. Cancer Incidence Report Saudi Arabia 1997-1998, 2001. Kingdom of Saudi Arabia. Ministry of Health National Cancer Registry, pp: 20-21.

2. Canadian Cancer Society, 2001. Key cancer statistics for 2001. http://www.Cancer.ca/English/RS_CancerFacts200 1.asp

3. Ferly, J., P. Pisani and D.M. Parkin 2001. Globocan 2000 IARC Cancer Base No.5. Lyon, International Agency for Research on Cancer Press.

4. Parker, R.G., K.M. Leung K.S. Rees, L.W. Bassett and A.P. Legorreta, 1999. Mammographic screening downstages breast carcinomas at time of diagnosis: A community-based experience. Breast J.,

$$
\text { 5: 359-363. }
$$
http://www.ncbi.nlm.nih.gov/pubmed/11348314

5. Fakhro, A.E. B.E. Fateha N. Al-Asheeri and S.A. Al-Ekri, 1999. Breast cancer: Patient characteristics and survival analysis at Salmaniya medical complex. Bahrain. Eastern Mediterranean Health J., 5: 430-439. http://www.ncbi.nlm.nih.gov/pubmed/10793821

6. Mahboubi, E., 1984. Epidemiology of cancer is Saudi Arabia, 1975-1985. Ann. Saudi Med., 7: 265-266.
7. Ellis, H. and P.J. Cox, 1984. Breast problems in 1000 consecutive referrals to surgical out patients. Postgrad Med. J., 60: 653-666. http://www.ncbi.nlm.nih.gov/pubmed/6494084

8. Chaudhry, M.A., J.L. Hayward, R.D. Bulbrook, M. Yoshida and S. Miura et al., 1991. A comparison of epidemiological characteristics in breast cancer patients and normal females in great Britain and Japan: Results of prospective study. Breast Cancer Res. Treat, 18: S19-S22. DOI: 10.1007/BF02633521

9. Lin, T.M., K.P. Chen and B. Macmahon, 1971. Epidemiologic characteristics of cancer of the breast in Taiwan. Cancer, 27: 1497-1504. DOI: 10.1002/1097-0142(197106)27:6<1497::AIDCNCR2820270634>3.0.CO;2-C

10. Hunt, K.K., 2001. Breast Cancer. Springer, Cairo, ISBN: 0387951903, pp: 520.

11. Abdel-Fattah, M. A. Zaki, A. Bassili, M. el-Shazly and G. Tognoni, 2000. Breast self-examination practice and its impact on breast cancer diagnosis in Alexandria, Egypt. Eastern Mediterr. Health J., 6: 34-40. http://www.ncbi.nlm.nih.gov/pubmed/11370338

12. Kolb, T.M., J. Lichy and J.H. Newhouse, 1998. Occult cancer in women with dense breasts: Detection with screening US-diagnostic yield and tumor characteristics. Radiology, 207: 191-199. http://www.ncbi.nlm.nih.gov/pubmed/9530316

13. Elmore, J.G., M.B. Barton, V.M. Moceri, S. Polk, P.J. Arena and S.W. Fletcher, 1998. Ten-year risk of false positive screening mammograms and clinical breast examinations. N. Engl. J. Med., 338: 1089-1096.

http://www.ncbi.nlm.nih.gov/pubmed/9545356

14. Amr, S.S., 1985. Breast diseases in Jordanian females: A study of 1000 cases. Eur. J. Surg. Oncol., 11: 257-262. http://www.ncbi.nlm.nih.gov/pubmed/2993034

15. Akhtar, S.S., T. Filani, M. Gadella and A. Amri, 1995. Beliefs and attitudes about breast selfexamination in Al-Qassim region of Saudi Arabia. A study of women attending primary health care centers. Saudi Med. J., 16: 493-497. http://cat.inist.fr/?aModele=afficheN\&cpsidt $=2979778$

16. Kelsey, J.L. and P.L. Horn-Ross, 1993. Breast cancer: Magnitude of the problem and descriptive epidemiology. Epidemiol. Rev., 15: 7-16. http://www.ncbi.nlm.nih.gov/pubmed/8405214

17. Ziegler, R.G. et al., 1993. Migration patterns and breast cancer risk in Asian-American women. J. Natl. Cancer Inst., 85: 1819-1827. http://www.ncbi.nlm.nih.gov/pubmed/8230262 